\title{
Effect of Synthesis Routes on Microstructure of Nanocrystalline Cerium Oxide Powder
}

\author{
Ashutosh Sharma \\ Department of Metallurgical and Materials Engineering, Indian Institute of Technology Kharagpur, Kharagpur, India. \\ Email: stannum.ashu@gmail.com
}

Received December $10^{\text {th }}, 2012$; revised June $10^{\text {th }}, 2013$; accepted June $28^{\text {th }}, 2013$

Copyright (C) 2013 Ashutosh Sharma. This is an open access article distributed under the Creative Commons Attribution License, which permits unrestricted use, distribution, and reproduction in any medium, provided the original work is properly cited.

\begin{abstract}
The effect of different processing routes on the microstructure of nanocrystalline ceria powder has been investigated. The nanocrystalline ceria is produced by solid state high energy ball milling (HEBM) and liquid state solution combustion synthesis (SCS) method. The liquid state route consists of a high temperature combustion reaction to form ceria from an aqueous solution of cerium ammonium nitrate (CAN) as an oxidizer and citric acid (CA) plus glycine (G) as mixed fuels. The powders have been characterized using techniques of X-ray diffraction (XRD), particle size analysis, scanning electron microscopy (SEM), and transmission electron microscopy (TEM). The microstructural characterizations show that the particle size distribution of the ball milled ceria powder is much wider than that of ceria produced by the SCS. The scanning electron micrographs show that the ball milled ceria powders are compact and dense structure while SCS ceria powders are scattered and porous.
\end{abstract}

Keywords: Ball Milling; Solution Combustion; Ceria; Nanocrystalline

\section{Introduction}

Nanocrystalline ceria has been a supreme choice for advanced engineering applications such as, electronic, photonic, fuel cells, sensing device etc., and therefore it cannot be ignored by present researchers [1-4]. In literature, there are several routes through which a nanocrystalline ceria can be achieved, for instance, high energy ball milling, spray deposition, magnetron sputtering, solution combustion synthesis, pulse electro- deposition, sol-gel method, hydrothermal techniques, etc. [5-9]. From economical point of view, modern researchers are very keen to use high energy ball milling technique to produce nanocrystalline powders owing to its simple and environmental friendly nature while the other methods are more expensive. They require high temperature maintenance, inert atmosphere and/or hazardous chemicals [6-9]. However, the solution combustion synthesis method is very quick and easy to talk about and also consumes less time. It involves a high temperature combustion of aqueous solution of an oxidiser and a fuel. Such a high temperature reaction can vaporize low boiling point constituents resulting in highly pure products [10]. However, the process needs a great care due to the explosive nature of the reactions involved [11].
In the present work, the effects of HEBM and SCS routes on the microstructure of nanoceria powders are evaluated. HEBM has been performed for 20 hs to obtain nano-sized ceria particles from as-received ceria powders. SCS has been carried out by using (a) CAN and G + CA, where $\mathrm{CAN}$ is cerium ammonium nitrate, $\mathrm{G}$ is glycine and $\mathrm{CA}$ is citric acid. The produced ceria powders have been characterized and compared for their particle size, size distribution and microstructural evolution.

\section{Experimental Procedure}

\subsection{Solid State Route-High Energy Ball Milling}

High energy ball milling (HEBM) of as received ceria powders (Loba Chemie, 99.8\%) is carried out using cemented tungsten carbide milling media with toluene as the process control agent. The mill (Fritsch Pulverissette-4, dual drive) is operated at a main disc speed $(\omega) 300 \mathrm{rpm}$ and planet speed of $(\Omega) 540 \mathrm{rpm}$ with a transmission ration $(\Omega / \omega)$ of 1.8. The transmission ratio is the ratio of the man disc speed $(\Omega)$ to the speed of the planets $(\omega)$. According to $(\Omega / \omega)$ the rotation speed choice, we can have the shock mode process (SMP) when $\Omega>>\omega$, and the friction mode processes (FMP) when $\Omega<<\omega$ [12]. For our case we selected the shock mode processes (SMP) 
for ceria for maximum shock power. The ball to powder is ratio is $10: 1$. After every hour of milling, the mill is allowed to cool for 45 to 60 minutes. Toluene pre- vents excessive cold welding of the powder particles. The powders are milled for $20 \mathrm{hs}$ and samples are col- lected regularly during milling to observe the progress of the size reduction. After attaining a reasonably small particle size, the mill is stopped and the powder is washed with distilled water and then with ethyl alcohol followed by drying in air.

\subsection{Liquid Processing-Solution Combustion Synthesis}

Nanocrystalline cerium oxide particles are synthesized by a modified combustion process occurring from aqueous solutions containing mixed fuels, i.e., CAN with CA plus G. This type of mixed fuels has been already used by several researchers in the past $[11,13]$. The aqueous solution is prepared by dissolving the stoichiometric amount of ceric ammonium nitrate $(\mathrm{CAN}),\left(\left(\mathrm{NH}_{4}\right)_{2} \mathrm{Ce}\right.$ $\left.\left(\mathrm{NO}_{3}\right)_{6}\right)$ (Loba chemie, $\left.99.5 \%\right)$ and glycine $(\mathrm{G})$ and citric acid (CA) (Merck, 99.7\%) in distilled water. The solution is then agitated in a beaker using magnetic stirrer for $3 \mathrm{~h}$. The resulting solution is kept in an electric furnace set at $200^{\circ} \mathrm{C}$. During the course of time, the solution evaporates, foams and then undergoes flameless combustion resulting in nanocrystalline product. This fine powder is very light and porous.

Assuming complete combustion, the theoretical equation for the formation of ceria can be written as follows:

$$
\begin{aligned}
& \mathrm{CAN}(\mathrm{aq})+(4 / 3) \mathrm{G}(\mathrm{aq})+(2 / 3) \mathrm{CA}(\mathrm{aq}) \\
& \rightarrow \mathrm{CeO}_{2}(\mathrm{~s})+(20 / 3) \mathrm{CO}_{2}(\mathrm{~g})+10 \mathrm{H}_{2} \mathrm{O}(\mathrm{g})+(14 / 3) \mathrm{N}_{2}(\mathrm{~g})
\end{aligned}
$$

This as synthesised ceria powder is still impure as it contains the undissolved gases which are finally removed by calcinations at $500^{\circ} \mathrm{C}$ for $2 \mathrm{~h}$ in a muffle furnace.

\section{Characterization}

\subsection{X-Ray Diffraction}

All the samples have been characterized in a Phillips $\mathrm{X}$-pert system diffractometer equipped with a $\mathrm{Cu}$ target operating at $40 \mathrm{kV}$ and $40 \mathrm{~mA}$ that provides X-rays with $\lambda=0.154 \mathrm{~nm}$. The particle size (d) and lattice strain $(\varepsilon)$ are calculated by the most common Scherrer formula:

$$
d=0.9 \lambda / B \cos \theta
$$

where, $\theta$ the Bragg angle and $\lambda$ is the wavelength of the $\mathrm{X}$-rays. The value of $B$ in (1) is obtained from the relation $B^{2}=B_{\mathrm{S}}^{2}-B_{\mathrm{m}}^{2}$,

where $B_{\mathrm{S}}$ is the full width at half maximum intensity of the most prominent peak of the sample. The $B_{\mathrm{m}}$, the instrumental broadening, is the full width at half maximum intensity of the corresponding peak from a strain free, coarse-grained sample.

However, there are contributions from both the lattice strain $\left(B_{\mathrm{ls}}\right)$ as well as the crystal size $\left(B_{\mathrm{cs}}\right)$ on peak broadening, which can be refined as follows:

The peak broadening due to the lattice strain is proportional to $\tan (\theta)$ and that due to the particle size is inversely proportional to $\cos (\theta)$

$$
\begin{gathered}
B_{\mathrm{cs}}=0.9\left(\frac{\lambda}{d \cos \theta}\right) \\
B_{\mathrm{ls}}=\varepsilon \tan (\theta)
\end{gathered}
$$

where $\varepsilon$ is the r.m.s. strain. Hence, the total broadening is

$$
B=0.9\left(\frac{\lambda}{d \cos \theta}\right)+\varepsilon \tan (\theta)
$$

On rearranging the terms, we get

$$
B \cos (\theta)=0.9\left(\frac{\lambda}{d}\right)+\varepsilon \sin (\theta)
$$

For the measurement of crystallite size $(d)$ and lattice strain $(\varepsilon)$ from the above relation, the following peaks of the ceria (111), (200), (220), (311), (222) and (400) are selected. When $B \cos (\theta)$ is plotted against $\sin (\theta)$, for different values of reflections, straight line is obtained with slope $(\varepsilon)$ and intercept at $0.9\left(\frac{\lambda}{d}\right)$, from where the crystallite size $(d)$ and lattice strain $(\varepsilon)$ can be determined [14].

\subsection{Particle Size Distribution}

The ceria powder particles are analysed for their particle size by a particle size distribution analyzer (MicrotracZetatrac). The measurement technique is that of dynamic light scattering of colloidal particles in suspension. A colloidal suspension of the powder particles is made in Triton X-100 solution. The velocity distribution of the particles suspended is known as function of particle size. Light scattered from each particle is Doppler-shifted by particle motion (Brownian motion). The optical system sends the signal to a photodetector and further analysed by Microtrac ${ }^{\circledR}$ FLEX Windows Software, using proprietary algorithms, to provide the particle size distribution.

\subsection{Electron Microscopy}

The morphology of the coatings and distribution of nanoceria particles are analysed using scanning electron microscope (Carl Zeiss Supra EVO 60) in secondary electron mode.

A transmission electron microscope (Philips Technai 2 Twin G220S) operating at $200 \mathrm{kV}$ is also used to characterize the ceria nanoparticles at higher resolution. The 
samples are prepared by ultrasonication of already dispersed ceria powder in alcohol for 5 hours. The final solution is then poured over a carbon coated grid followed by drying in open atmosphere, and then stored at room temperature for characterization.

\section{Results and Discussions}

\subsection{X-Ray Diffraction}

Figures 1(a)-(c) shows the X-ray diffraction patterns of the nanocrystalline cerium oxide powder (a) ball milled for 0 to $20 \mathrm{hs}$, the inset shows the broadening of the (111) peak with milling time, (b) change in particle size with milling time for $20 \mathrm{hs}$ and (c) X-ray pattern for solution combustion synthesized ceria powder. The average particle size and lattice strain of ceria powder are calculated from the X-ray diffraction patterns and are shown in Table 1.

It is noted that from Table $\mathbf{1}$ that the particle size and lattice strain of ball milled ceria varies from $191 \mathrm{~nm}(0 \mathrm{~h})$ to $32 \mathrm{~nm}(20 \mathrm{~h})$. However, the lattice strain increases from $0.49 \times 10^{-3}(0 \mathrm{~h})$ to $1.14 \times 10^{-3}(15 \mathrm{~h})$ ball milled ceria and then it decreases to $1.06 \times 10^{-3}$ with further milling at 20 hs due to cold welding of the powder particles. It has been reported already that the individual particles get rotated in a way to minimize the lattice strain [15], while for the ceria produced by the SCS method, the calculated particle size is $20-30 \mathrm{~nm}$ and lattice strain is $(0.191-0.392) \times 10^{-3}$.

\subsection{Particle Size Distribution Analysis}

From Figure 2(a) it is observed that the size distribution of the ball milled ceria powder particles follows uni modal distribution with particle size varying from 28 to 570 $\mathrm{nm}$. The mean value of the particle size distribution lies round $90 \mathrm{~nm}$.

While the ceria produced by SCS method possess bimodal particle size distribution (Figure 2(b)). The first group of particles varies from 60 to $85 \mathrm{~nm}$ with a mean value of $58 \mathrm{~nm}$, and while the second group comprises of particles in range $500-800 \mathrm{~nm}$ with a mean value of 452

Table 1. Crystallite size and lattice strain.

\begin{tabular}{cccc}
\hline Solid Route & HEBM & $\begin{array}{c}\text { Crystallite Size } \\
(\mathrm{nm})\end{array}$ & $\begin{array}{c}\text { Lattice Microstrain } \\
(\%) \times 10^{-3}\end{array}$ \\
\hline $0 \mathrm{~h}$ & 191 & 0.49 \\
$5 \mathrm{~h}$ & 69 & 0.65 \\
& $10 \mathrm{~h}$ & 43 & 0.79 \\
& $15 \mathrm{~h}$ & 39 & 1.14 \\
& $20 \mathrm{~h}$ & 32 & 1.06 \\
Liquid Route & $\mathrm{SCS}$ & $20-30$ & $0.191-0.392$ \\
\hline
\end{tabular}
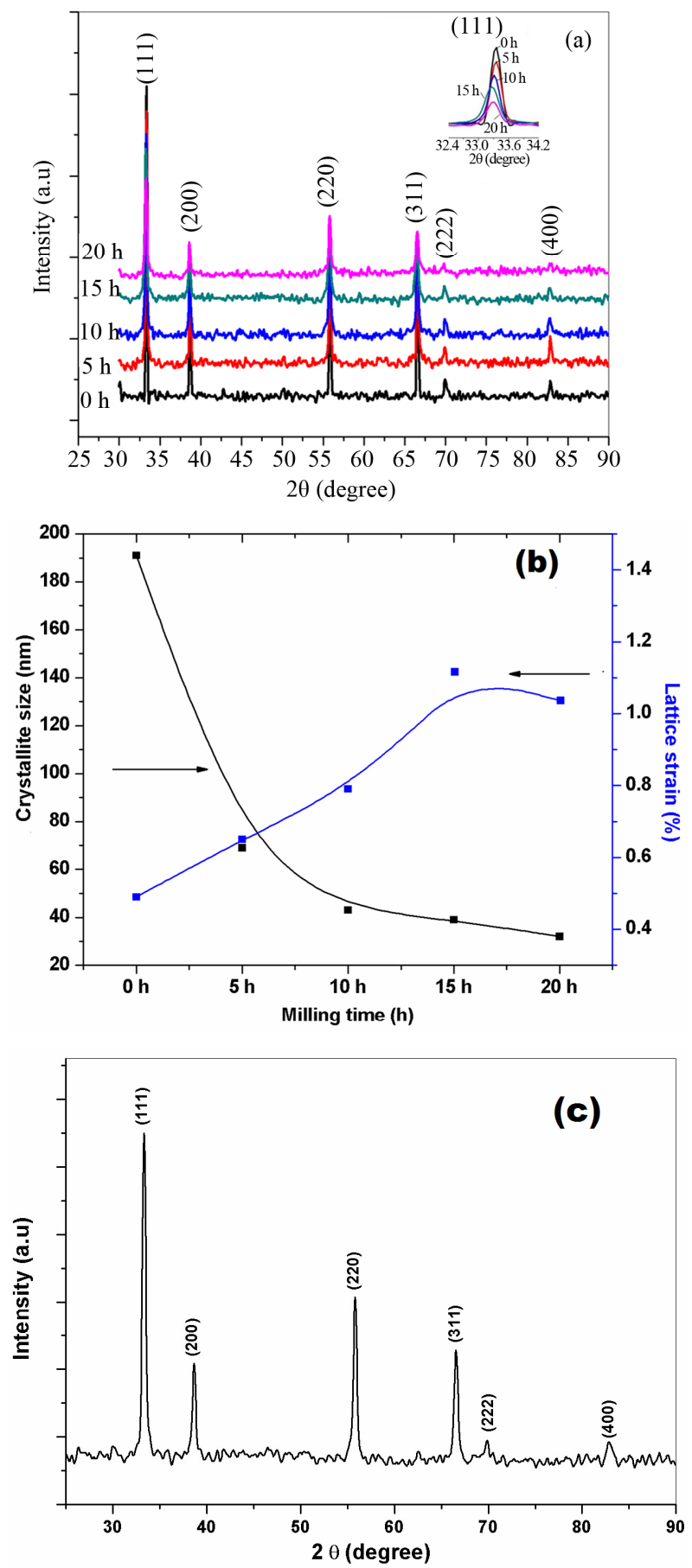

Figure 1. (a) $X$-ray diffraction patterns of $(0,5,10,15$, and 20) hours ball milled ceria, (b) effect of milling time on particle size and lattice strain of ball milled ceria, and (c) X-ray diffraction pattern for solution combustion synthesized ceria.

$\mathrm{nm}$. This indicates a greater tendency of ceria produced by SCS towards agglomeration. The degree of agglomeration in combustion synthesized ceria is well maintained at higher temperatures and is much higher as compared to that of ball milled ceria [16]. 


\subsection{Electron Microscopy}

\subsubsection{SEM}

It is observed from Figures 3(a)-(b) that the particle size of ceria is significantly reduced after ball milling and particle size is more or less uniform. The particles are faceted, free from porosity and irregular shaped in structure due to the continuous welding and fracturing and cold welding in due course of ball milling.

However, in case of ceria produced by SCS method, particles are present in the form of different sized lumps or flakes with rounded shaped structures, Figure 3(c). This type of structures are generated due to the explosive nature of this reaction where gases evolve out giving rise to porosity, and thus the ceria produced by SCS shows a higher tendency towards agglomeration. The porous structure of the combustion synthesised powder was related with the structural rearrangement due to crystallization of the particles after calcinations [17].

\subsubsection{TEM}

From Figure 4, it is observed that ball milled ceria possess a range of particle size from $10 \mathrm{~nm}$ to $50 \mathrm{~nm}$ which are irregular shaped as show in Figure 4(a). However, in case of combustion synthesized ceria the particle size is narrower, few particles are even approx. $10 \mathrm{~nm}$ (Figure 4(b)).

The ball milled ceria particles exhibits mixed formation of ring and spot diffraction pattern as shown in Figure 4(c). In case of the ceria produced by SCS, the diffrac-
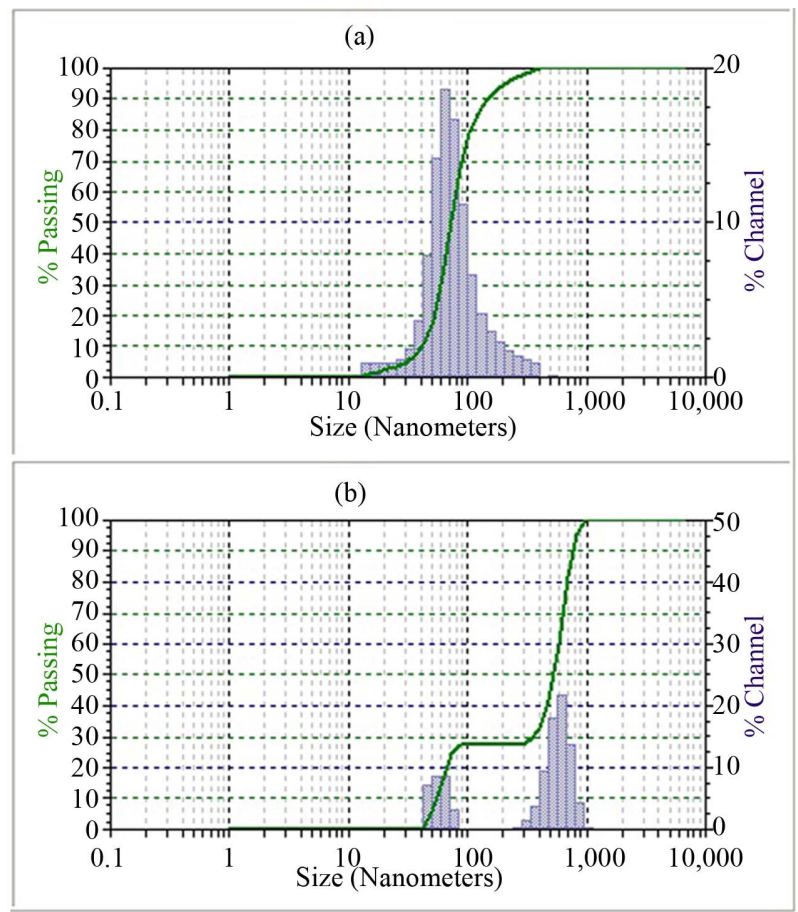

Figure 2. Particle size distribution of ceria (a) $20 \mathrm{~h}$ ball milled and (b) solution combustion synthesized ceria. tion pattern consists of intense concentric rings, Figure 4(d). These sharp rings are due to numerous single crystal diffraction from the randomly oriented crystals signifying

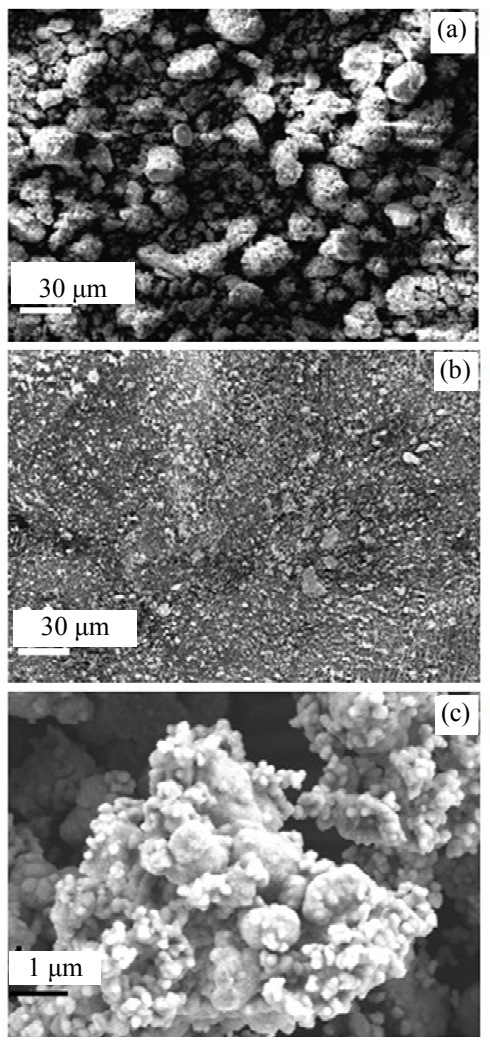

Figure 3. SEM micrograph of ceria powder prepared by ball milling (a) $0 \mathrm{~h}$, (b) $20 \mathrm{~h}$ and (c) solution combustion synthesized ceria.
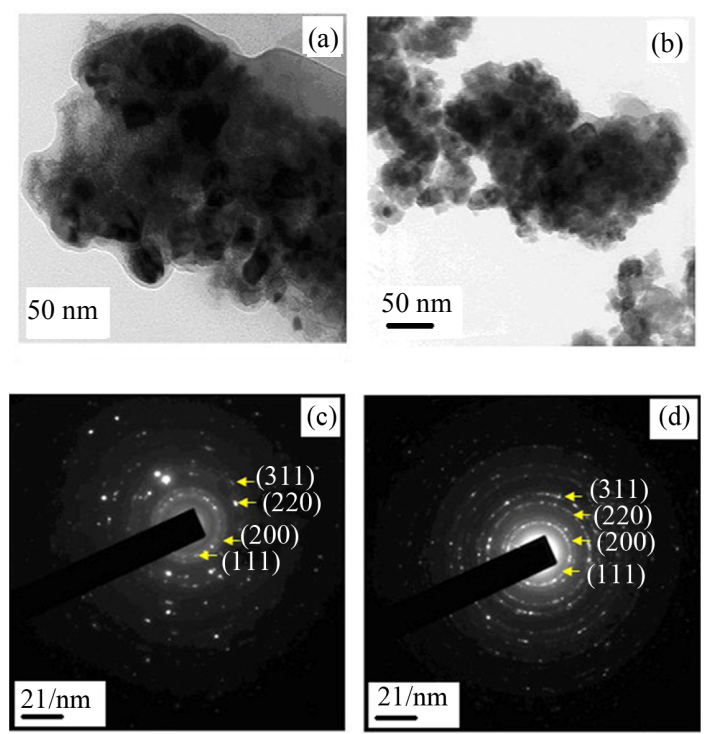

Figure 4. TEM micrographs of (a) 20 hs ball milled ceria powder and (b) combustion synthesized ceria powder; SAD patterns (c) $20 \mathrm{~h}$ ball ceria milled powder and (d) combustion synthesized ceria powder. 
a finer crystallite sizes as compared to ball milled ceria powder particles.

\section{Conclusions}

1) The nanocrystalline ceria powder is successfully produced by both high energy ball milling and solution combustion synthesis methods.

2) The particle size distribution of ball milled ceria ( 28 - $570 \mathrm{~nm}$ ) possesses a mean value of $90 \mathrm{~nm}$ as compared to that of combustion synthesized powder with a bimodal distribution $(60-85 \mathrm{~nm}$, and $500-800 \mathrm{~nm})$ with mean values of $58 \mathrm{~nm}$ and $450 \mathrm{~nm}$ respectively.

3) There is significant porosity in solution combustion synthesized ceria as compared to that of ball milled ceria. The stability of porous structure of ceria produced by SCS at higher temperatures is the key to fabrication of new ordered and application in ceramic engineering. Thus, ceria produced by SCS route can be a better candidate for sensing applications.

\section{REFERENCES}

[1] H.-L. Chen, M.-H. Weng, S.-P. Ju, J.-G. Chang, H.-T. Chen and C.-S. Chang, "Structural and Electronic Properties of $\mathrm{Ce}_{n} \mathrm{O}_{2 n}(n=1-5)$ Nanoparticles: A Computational Study," Journal of Molecular Structure, Vol. 963, No. 1, 2010, pp. 2-8. doi:10.1016/j.molstruc.2009.09.019

[2] P. Knauth and H. L. Tuller, "Solute Segregation, Electrical Properties and Defect Thermodynamics of Nanocrystalline $\mathrm{TiO}_{2}$ and $\mathrm{CeO}_{2}$," Solid State Ionics, Vol. 136-137, 2000, pp. 1215-1224. doi:10.1016/S0167-2738(00)00588-9

[3] Y. L. Xuan, J. Hu, K. L. Xu, X. D. Hou and Y. Lv, "Development of Sensitive Carbon Disulfide Sensor by Using Its Cataluminescence on Nanosized-CeO $\mathrm{C}_{2}$," Sensors and Actuators B, Vol. 136, 2009, pp. 218-223.

doi:10.1016/j.snb.2008.10.014

[4] G. I. N. Waterhouse and M. R. Waterland, "Opal and Inverse Opal Photonic Crystals: Fabrication and Characterization," Polyhedron, Vol. 26, 2007, pp. 356-368. doi:10.1016/j.poly.2006.06.024

[5] Alan V. Chadwick and Shelley L.P. Savin, "EXAFS Study of Nanocrystalline $\mathrm{CeO}_{2}$ Samples Prepared by Sol-Gel and Ball-Milling Routes," Journal of Alloys and Compounds, Vol. 488, 2009, pp. 1-4. doi:10.1016/j.jallcom.2006.10.164

[6] H. S. Kang, Y. C. Kang, H. Y. Koo, S. H. Ju, D. Y. Kim, S. K. Hong, J. R. Sohn, K. Y. Jung and S. B. Park, "NanoSized Ceria Particles Prepared by Spray Pyrolysis Using Polymeric Precursor Solution," Materials Science and
Engineering B, Vol. 127, No. 2-3, 2006, pp. 99-104. doi:10.1016/j.mseb.2005.09.063

[7] A. Q. Wang, P. Punchaipetch, R. M. Wallace and T. D. Golden, "X-Ray Photoelectron Spectroscopy Study of Electrodeposited Nanostructured $\mathrm{CeO}_{2}$ Films," Journal of Vaccum Science Technology B, Vol. 21, No. 3, 2003, p. 1169. doi:10.1116/1.1577569

[8] S. Kanakaraju, S. Mohan and A. K. Sood, "Optical and Structural Properties of Reactive Ion Beam Sputter Deposited $\mathrm{CeO}_{2}$ Films," Thin solid films, Vol. 305, No. 1-2, 1997, pp. 191-195. doi:10.1016/S0040-6090(97)00081-3

[9] Y. Konishi, S. Asai, T. Murai and H. Takemori, "Preparation of Fine Ceria Powders by Cerium(IV) Carboxylate Solutions," Metallurgical and Materials Transactions $B$, Vol. 28, 1997, pp. 959-961.

[10] John J. Moore and H. J. Feng, "Combustion Synthesis of Advanced Materials: Part I. Reaction Parameters," Progress in Materials Science, Vol. 39, 1995, pp. 243-273. doi:10.1016/0079-6425(94)00011-5

[11] R. D. Purohit, B. P. Sharma, K. T. Pillai and A. K. Tyagi, "Ultrafine Ceria Powders via Glycine-Nitrate Combustion," Materials Research Bulletin, Vol. 36, No. 15, 2001, pp. 2711-2721. doi:10.1016/S0025-5408(01)00762-0

[12] R. Hamzaoui, O. Elkedim and E. Gaffet, "Milling Conditions Effect on Structure and Magnetic Properties of Mechanically Alloyed Fe-10\% Ni and Fe-20\% Ni Alloys," Materials Science and Engineering A, Vol. 381, No. 1-2, 2004, pp. 363-371. doi:10.1016/j.msea.2004.05.008

[13] K. C. Patil, S. T. Aruna and T. Mimani, "Combustion Synthesis: An Update," Current Opinion in Solid State and Materials Science, Vol. 6, No. 6, 2002, pp. 507-512. doi:10.1016/S1359-0286(02)00123-7

[14] C. Suryanarayana, "Mechanical Alloying and Milling," Marcell Dekker, New York, 2004. doi:10.1201/9780203020647

[15] H. J. Fecht, Nanophasematerials-Syntheses, Properties and Applications: Proceedings of the NATO Advanced Study Institute on, Kluwer Academic Publishers, 1994, p. 125

[16] S. T. Mukherjee, V. Bedekar, A. Patra, P. U. Sastry and A. K. Tyagi, "Study of Agglomeration Behavior of Combustion-Synthesized Nano-Crystalline Ceria Using New Fuels," Journal of Alloy and Compounds, Vol. 466, No. 1-2, 2008, pp. 493-497. doi:10.1016/j.jallcom.2007.11.070

[17] R. P. S. Chakradhar, B. M. Nagabhushana, G. T. Chandrappa, K. P. Ramesh and J. L. Rao, "Solution Combustion Synthesis Derived Nanocrystalline Macroporous Wollastonite Ceramics-Review," Materials Chemistry and Physics, Vol. 95, No. 1, 2006, pp. 169-175. doi:10.1016/j.matchemphys.2005.06.002 